\title{
On the motion of dayside auroras caused by a solar wind pressure pulse
}

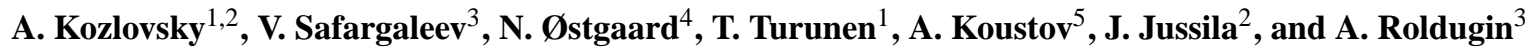 \\ ${ }^{1}$ Sodankylä Geophysical Observatory, Sodankylä, FIN-99600, Finland \\ ${ }^{2}$ Department of Physical Sciences, University of Oulu, Oulu, FIN-90014, Finland \\ ${ }^{3}$ Polar Geophysical Institute, Apatity, 18 4200, Russia \\ ${ }^{4}$ Space Sciences Laboratory, University of California, 7 Gauss Way, Berkeley, CA 94 720-7450, USA \\ ${ }^{5}$ Department of Physics and Engineering Physics, University of Saskatchewan, Saskatoon, SK S7N 5E2, Canada
}

Received: 13 January 2004 - Revised: 26 October 2004 - Accepted: 19 November 2004 - Published: 28 February 2005

\begin{abstract}
Global ultraviolet auroral images from the IMAGE satellite were used to investigate the dynamics of the dayside auroral oval responding to a sudden impulse (SI) in the solar wind pressure. At the same time, the TV all-sky camera and the EISCAT radar on Svalbard (in the pre-noon sector) allowed for detailed investigation of the auroral forms and the ionospheric plasma flow. After the SI, new discrete auroral forms appeared in the poleward part of the auroral oval so that the middle of the dayside oval moved poleward from about $70^{\circ}$ to about $73^{\circ}$ of the AACGM latitude. This poleward shift first occurred in the 15 MLT sector, then similar shifts were observed in the MLT sectors located more westerly, and eventually the shift was seen in the 6 MLT sector. Thus, the auroral disturbance "propagated" westward (from 15 MLT to 6 MLT) at an apparent speed of the order of $7 \mathrm{~km} / \mathrm{s}$. This motion of the middle of the auroral oval was caused by the redistribution of the luminosity within the oval and was not associated with the corresponding motion of the poleward boundary of the oval. The SI was followed by an increase in the northward plasma convection velocity. Individual auroral forms showed poleward progressions with velocities close to the velocity of the northward plasma convection. The observations indicate firstly a pressure disturbance propagation through the magnetosphere at a velocity of the order of $200 \mathrm{~km} / \mathrm{s}$ which is essentially slower than the velocity of the fast Alfvén (magnetosonic) wave, and secondly a potential (curl-free) electric field generation behind the front of the propagating disturbance, causing the motion of the auroras. We suggest a physical explanation for the slow propagation of the disturbance through the magnetosphere and a model for the electric field generation. Predictions of the model are supported by the global convection maps produced by the SuperDARN HF radars. Finally, the interchange instability and the eigenmode toroidal Alfvén oscillations are
\end{abstract}

Correspondence to: A. Kozlovsky

(alexander.kozlovsky@oulu.fi) discussed as possible generation mechanisms for the dayside auroral forms launched by the SI.

Key words. Magnetospheric physics (Auroral phenomena; Solar wind-magnetosphere interactions; Electric fields)

\section{Introduction}

Response of the Earth's magnetosphere-ionosphere system to sudden changes in the solar wind dynamic pressure (SWP) has been under intense investigation over the last several decades. Analysis of the ground-based magnetometer data allowed us to generally understand the electric field and currents associated with the SWP changes (Sibeck, 1990; Araki, 1994). This has been achieved due to advantages of the magnetometers, such as their global coverage and capability to continuously monitor the Earth's magnetic field.

The situation is less clear with respect to the optical aurora signatures of the SWP variations. Much fewer papers have been published in this area because of difficulties in obtaining required data. One can observe the dayside auroras, responding to variations of the solar wind parameters, from the ground, but this is only possible at very high-latitude regions during a short dark-sky period of the polar winter. Such observations were performed at Svalbard (magnetic latitudes of $70^{\circ}-76^{\circ}$ ) by Vorobyev (1977) and Sandholt et al. (1994), who reported that enhancements of the solar wind dynamic pressure can lead to equatorward shifts in the cusp/cleft aurora. One can monitor the global distribution of the auroral luminosity, including the dayside auroras, by using the satellite ultraviolet imagers (UVI), though these measurements have worse spatial $(\sim 100 \mathrm{~km})$ and temporal $(\geq 2 \mathrm{~min})$ resolutions. Using the ultraviolet imager on the Polar spacecraft, Brittnacher et al. (2000) observed that a pressure pulse can cause the equatorward shift of the low-latitude boundary of the dayside aurora, in agreement with earlier ground-based observations. 


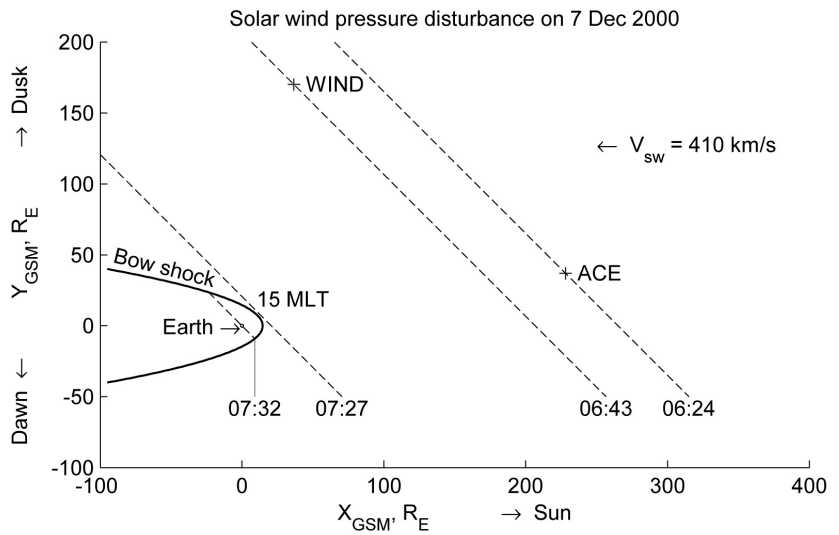

Fig. 1. Orientation of the solar wind dynamic pressure front (dashed lines) in the X-Y plane as observed by the WIND and ACE spacecrafts. The disturbance arrived at the bow shock near the 15 MLT sector.

Significant changes in the auroral oval location, its size and its intensity in response to solar wind pressure variations were demonstrated by Boudouridis et al. (2003), who studied particle precipitation data from the Defense Meteorological Satellite Program (DMSP) low-altitude satellites. Most prominent observed features were an increase in the auroral zone luminosity band and a decrease in the polar cap size after the solar wind dynamic pressure increase, under the steady southward IMF conditions.

Explanation of the motion of auroras during SWP changes is not obvious in the frame of the basic concepts of the solar wind-magnetosphere interaction. It is well known that when highly-conducting plasma of the solar wind encounters the Earth's magnetic field, the Lorenz's force deflects the ions and electrons in opposite directions. As a result, a large-scale duskward Chapman-Ferraro (DCF) current develops on the dayside magnetopause, and this current cancels the Earth's dipole magnetic field outside the magnetosphere. At the same time, the magnetic field is increased inside the magnetosphere, so one can say the solar wind compresses the magnetosphere. The magnitude of the compression field $\left(\boldsymbol{B}_{C F}\right)$ is related to the intensity of the DCF currents $\left(\boldsymbol{J}_{C F}\right)$; the larger the solar wind pressure (and, hence, $\boldsymbol{J}_{C F}$ ), the larger the $\boldsymbol{B}_{C F}$. Thus, changes in the solar wind pressure produce corresponding changes in the magnetospheric magnetic field. The latter results in the setting up of an induced (i.e. divergence-free, $\nabla \cdot \boldsymbol{E}=0$ ) electric field described by Faraday's law,

$\nabla \times \boldsymbol{E}_{\text {ind }}=-\partial \boldsymbol{B}_{C F} / \partial t$

This electric field forces the magnetospheric plasma to move with a velocity of the electric drift,

$\boldsymbol{V}_{P s w}=\boldsymbol{E}_{\text {ind }} \times \boldsymbol{B} / B^{2}$.

This motion is directed toward the Earth for the increasing solar wind pressure. Importantly, the induced electric field is not transmitted along the magnetic field lines from the magnetosphere to the ionosphere, contrary to a potential (curlfree) electric field. This means that the induced electric field changes the shape of the magnetic flux tubes, but does not cause a noticeable drift motion of the ionospheric footprints of the tubes. In other words, such a motion of the magnetospheric plasma is not mapped into the ionosphere.

However, one can expect at least two other types of auroral motions that follow SWP changes. Firstly, there can be a shift in the location of the boundary between the open and closed magnetic field tubes (OCB). One can relate such a shift to a change in the rate of reconnection (i.e. erosion of the magnetic field lines). In this case, motion of the auroral oval poleward boundary is not related to plasma convection. Secondly, motion of the auroras can be caused by the potential electric field generated in the magnetosphere by the solar wind pressure impact. Contrary to the induced electric field discussed earlier, the potential (curl-free) electric field is caused by an electric charge separation and can be transmitted along the highly-conducting magnetic field lines from the magnetosphere to the ionosphere. In this case, motion of individual auroral forms would correspond to motion of the magnetic flux tubes drifting with the convection velocity. Both effects (OCB change and plasma convection) can lead to motion of the auroras, however, in both cases one would need additional arguments to identify the cause of this motion, the reconnection rate change or the generation of potential electric field, respectively.

In the present study we investigate how the dayside motion of auroras associated with the SWP changes is related to plasma convection. To achieve this, we use global (satellite UVI) and local (TV camera on the ground) auroral observations in conjunction with radar measurements of the ionospheric plasma flows. We also discuss the physics behind the observations.

\section{Event of 7 December 2000: Solar wind and IMF con- ditions}

In this paper we study in detail one event, 7 December 2000, between 07:00 and 08:00 UT. Conditions in the solar wind and the IMF were monitored by the Advanced Composition Explorer (ACE) and Wind spacecrafts located at [X, Y, $\mathrm{Z}]_{\mathrm{GSM}}=[228,37,-17] \mathrm{R}_{E}$ and $[\mathrm{X}, \mathrm{Y}, \mathrm{Z}]_{\mathrm{GSM}}=[37,170,-46]$ $\mathrm{R}_{E}$, respectively, see their positions in the $\mathrm{X}-\mathrm{Y}$ plane on Fig. 1. ACE observed a sudden impulse (SI) in the solar wind dynamic pressure with an increase from 3 to $7 \mathrm{nPa}$ at 06:24 UT. Wind detected this disturbance about $20 \mathrm{~min}$ later, at $06: 43$ UT. For an average solar wind speed of $410 \mathrm{~km} / \mathrm{s}$, one can interpret this time difference as a result of a $48^{\circ}$ tilt of the SI front (dashed lines in Fig. 1) with respect to the EarthSun line (in the X-Y plane). Such a tilt means that the SI hit the magnetosphere in the post-noon sector at about 15 MLT. The estimated time for the SI arrival to the bow shock (assuming the bow shock (BS) at 14.6 $\mathrm{R}_{E}$ ) was 07:27 UT. 
This value agrees well with the magnetic field increase observed at 07:32 UT at the low-latitude magnetic observatory Bangui (BNG, $\left.4,4^{\circ} \mathrm{N}, 18.6^{\circ} \mathrm{E}\right)$. The 5-min time difference (07:27 UT versus 07:32 UT) can be attributed to the disturbance propagation time through the magnetosheath.

Figure 2 presents the solar wind dynamic pressure and the interplanetary magnetic field (IMF), measured by the ACE and Wind spacecrafts. The data are time-shifted by 63 and $44 \mathrm{~min}$, respectively, to account for propagation from the spacecrafts to the BS. The vertical dashed line indicates the time of the pressure front arrival to the BS. The middle panel shows the north $(\mathrm{X})$ component of the magnetic field measured at Bangui, and the start time for the magnetic disturbance is indicated by the vertical dotted line.

In the following discussion, we focus on the time interval from 07:20 UT to 08:00 UT, for which the magnetosphere was responding to the SI. During this interval, the far ultraviolet (FUV) imaging system on the Imager for Magnetopauseto-Aurora Global Exploration (IMAGE) satellite (Mende et al., 2000a) observed the entire auroral oval in the Northern Hemisphere. We used the Wideband Imaging Camera (WIC) (Mende et al., 2000b) data obtained every 2 min with 10-s image exposure. As an example, Fig. 3 presents two global WIC images taken before (07:23 UT, panel A) and after (07:42 UT, panel B) the SWP jump; these moments are indicated by corresponding letters in Fig. 2, middle panel. The images are given in the Altitude Adjusted Corrected Geomagnetic (AACGM) coordinate system (for which any two points connected by a magnetic field line have the same AACGM coordinates). The red circle in the pre-noon sector shows the field-of-view of the TV all-sky camera (ASC) at Barentsburg $\left(\mathrm{BAB}, 78.1^{\circ} \mathrm{N}, 14.2^{\circ} \mathrm{E}\right)$ on Svalbard while the red triangle indicates the position of the European Incoherent Scatter radar on Svalbard (ESR, 78.2 $\left.{ }^{\circ} \mathrm{N}, 16.1^{\circ} \mathrm{E}\right)$. The red line indicates the radar beam orientation. To investigate the motion of the dayside auroral oval responding to the SI, we used a sequence of WIC images taken between 07:20 UT and 08:00 UT.

\section{Auroral oval dynamics}

To analyze quantitatively the motion of the auroral oval on the global UV images, one needs to characterize its location quantitatively. On the WIC images, the typical UV intensity in the polar cap is 170-190 R (Rayleigh), and this intensity can be considered as the noise level. At the poleward boundary of the auroral oval, the intensity sharply increases above $200 \mathrm{R}$. Within the auroral oval, the UV intensity typically exceeds $250 \mathrm{R}$. In this study, we consider two parameters of the oval, the location of its middle part and the location of its poleward boundary. The position of the middle of the auroral oval was represented by a line given as a harmonic function of magnetic local time $M_{L T}$ :

$R_{A}=\sum_{k=0}^{3}\left(a_{k}^{c} \cos \left(2 \pi k \frac{M_{L T}}{24}\right)+a_{k}^{s} \sin \left(2 \pi k \frac{M_{L T}}{24}\right)\right)$.

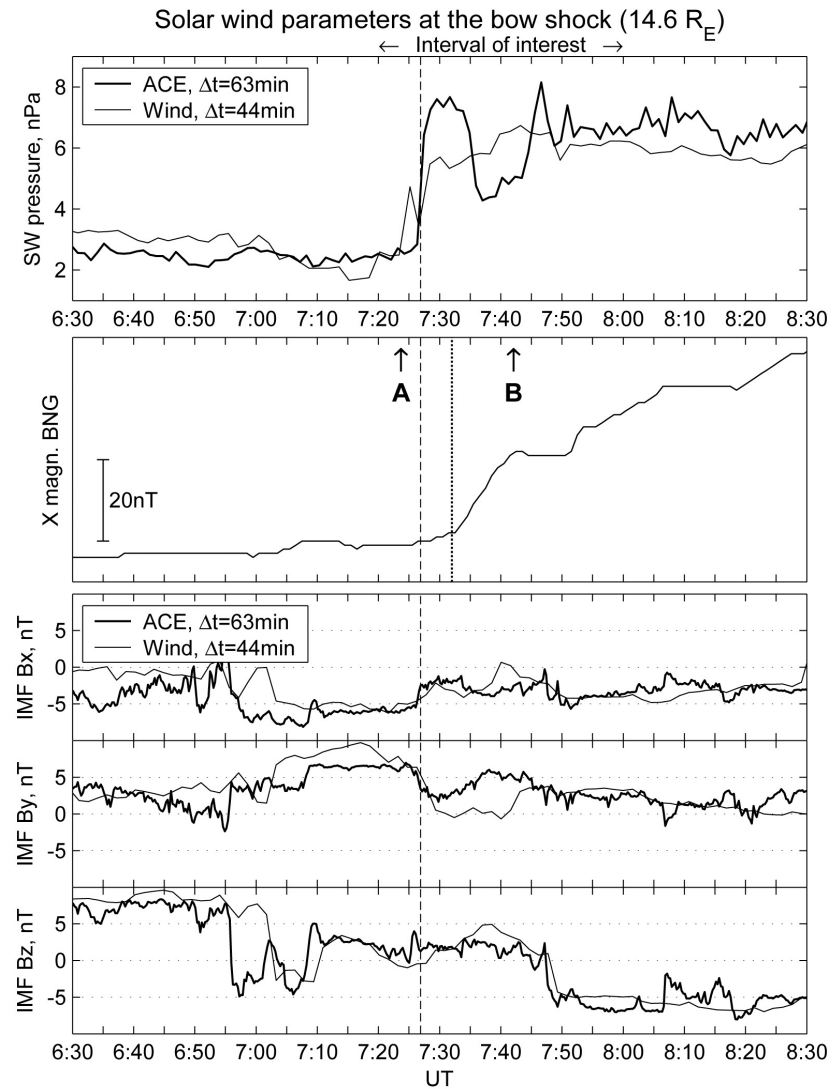

Fig. 2. Solar wind and IMF parameters time shifted to account for the propagation delay from the satellites to the bow shock. Vertical dashed and dotted lines indicate the moments of the pulse arrival at the bow shock and the detection of its response at the low-latitude magnetic observatory Bangui, respectively. Letters A and B denote the moments for which global auroral images will be considered (Fig. 3).

Here $R_{A}$ is the AACGM co-latitude (i.e. a distance from the geomagnetic pole) of the middle of the auroral oval. Coefficients $a_{k}$ were calculated by minimizing the following integral:

$\iint\left(R_{A}\left(M_{L T}\right)-R\right)^{2} \times$

$\left\{\begin{array}{l}\left(I\left(R, M_{L T}\right)-I_{0}\right), \text { if } I>I_{0} d R d M_{L T} . \\ 0, \text { if } I<I_{0}\end{array}\right.$

Here $R$ and $M_{L T}$ are the co-latitude and local time of a pixel in the WIC frame, and $I$ is the UV intensity in this pixel. The threshold intensity $I_{0}$ (selected as $260 \mathrm{R}$ in this study) was used for rejecting the background low-intensity pixels both poleward and equatorward of the auroral oval. The integration was performed over an area poleward of $60^{\circ}$ AACGM latitude, excluding the sunlight region near noon. Minimization of integral (4) means that, at each local time, integrated UV power values poleward and equatorward of the middle line are equal. Examples of the middle of the auroral oval location determined by the above method are shown by white closed curves in Fig. 3 for the entire oval. 
A

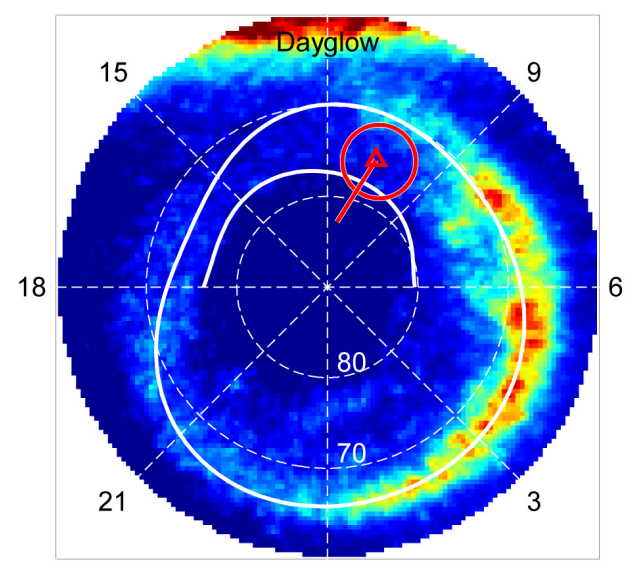

07:23:41
B

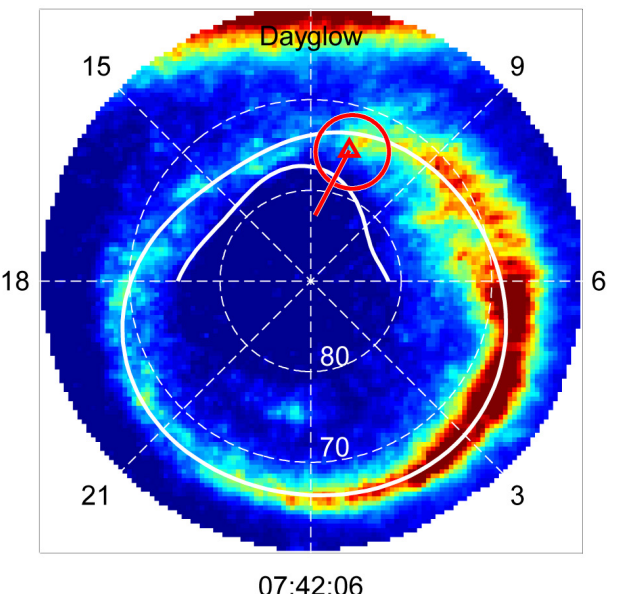

07:42:06

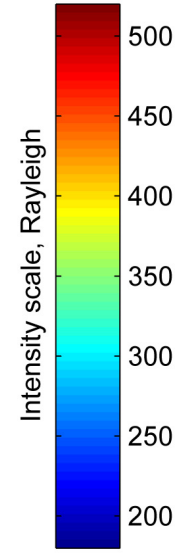
$\infty$

Fig. 3. Global UV images from the IMAGE satellite taken before (A) and after (B) the sudden impulse arrival. White lines indicate the center and the poleward boundaries of the auroral oval (determined with an algorithm described in the text). Red circle shows the field of view of the Barentsburg TV camera, and red line shows the incoherent scatter radar beam position. The images are given in the AACGM coordinates.

To characterize the poleward boundary (PB) of the oval, we considered a contour line corresponding to a certain brightness threshold; a similar method for the PB identification was earlier used by Brittnacher et al. (1999) and Baker et al. (2000). From the WIC images, we estimated that the mean intensity in the polar cap was $170 \mathrm{R}$, and the maximum intensity in the polar cap was $190 \mathrm{R}$, which should be attributed to random noise. The threshold should be as close as possible to the mean PC intensity (170 R). On the other hand, it should slightly exceed the maximum noise level (190 R). The value of $200 \mathrm{R}$ is close to this optimum value. Thus, we introduced the PB as a contour line corresponding to the UV intensity of $200 \mathrm{R}$. Experimental points on the PB location were approximated by a smooth line, in a form similar to Eq. (3):

$R_{P B}=\sum_{k=0}^{3}\left(b_{k}^{c} \cos \left(2 \pi k \frac{M_{L T}}{24}\right)+b_{k}^{s} \sin \left(2 \pi k \frac{M_{L T}}{24}\right).\right)$

Coefficients $b_{k}$ were calculated for each image by using the least-square method. The poleward boundary has been determined only on the dayside. This is because on the nightside such a determination would be ambiguous in the presence of the double oval and we are not considering the nightside phenomena in the present study. The latitudinal position of the 200-R contour line was determined with an average uncertainty of $0.6^{\circ}$ (for some frames and MLT sectors the uncertainty was up to $1.0^{\circ}$ ), which is of the same order as the spatial resolution of WIC (59 km in our case). One should emphasize that the contour line of the UV intensity (referred to as the PB) may not coincide with the magnetospheric open-closed boundary (or with a boundary of particle precipitation region). Indeed, Baker et al. (2000) compared the boundaries from Polar UVI images with the precipitation boundaries from DMSP satellite spectrograms in the evening sector and discovered a systematic latitudinal offset between UVI and DMSP of approximately $1^{\circ}$. An additional systematic error may occur because of the arbitrariness in the selection of the intensity threshold. However, in this study we focus on the motion of the auroral oval so that the systematic errors are not as important. The poleward boundaries of the auroral oval are shown as second white lines in the dayside sector (6-18 MLT) of Fig. 3.

After the positions of the middle and poleward boundary of the oval were determined for each WIC frame, the latitudes were presented by a color diagram in coordinates of MLT time UT time (Fig. 4). We indicate in Fig. 4 the time for the SI occurrence in the same way as in Fig. 2, i.e. dashed lines show the time of the SI arrival to the BS and dotted lines show the start time for the low-latitude magnetic disturbance on the ground. Black arrows at 15 MLT indicate that the SI hit the magnetosphere in this MLT sector.

The clearest feature seen in the top panel in Fig. 4 is that after the SI, the middle part of the dayside auroral oval moved poleward from about $70^{\circ}$ to about $73^{\circ}$ AACGM latitude. This poleward motion was first seen in the 15 MLT sector at about 07:32 UT, later it occurred in the more westerly located MLT sectors, and finally, it reached the 6 MLT sector at $07: 45$ UT. Thus, the auroral motion was propagating westward, from the 15 MLT sector to the 6 MLT sector at a velocity of the order of $7 \mathrm{~km} / \mathrm{s}$. There were no indications of such motion eastward of the 15 MLT sector and on the nightside. In the rest of the paper we will mainly pay attention to this motion of the middle of the auroral oval.

Some other features may also be seen in Fig. 4. At 07:32 UT the entire oval in the 15-07 MLT sector has been shifted poleward. In the next frame, at 07:34 UT it moved back equatorward, and then at 07:36 UT, it again moved poleward. Such motion may indicate a fast (within 2-4 min) 

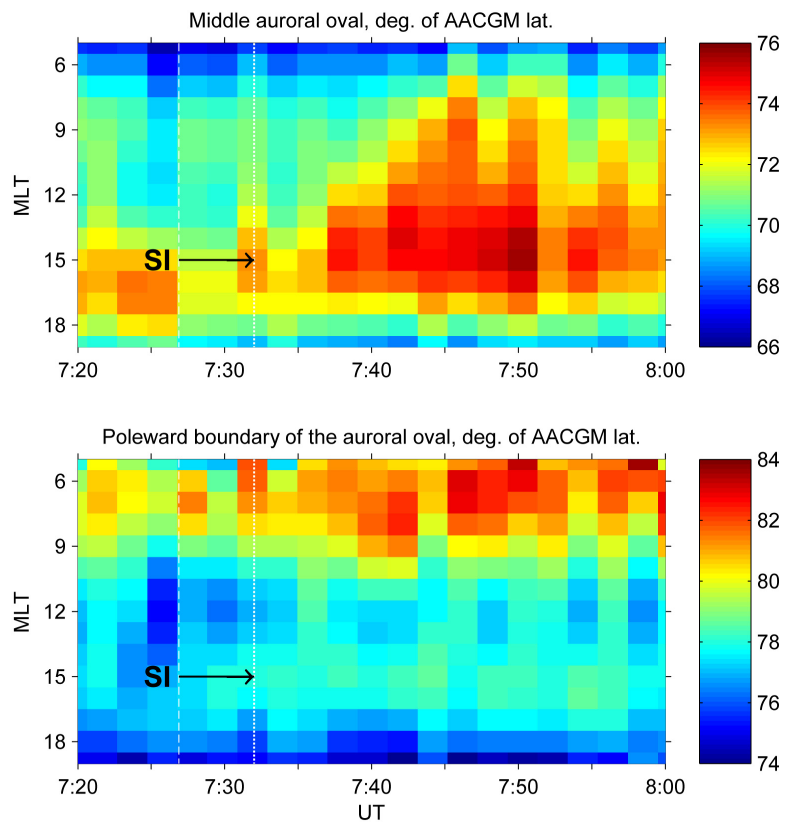

Fig. 4. Locations of the auroral oval middle part and the auroral oval poleward boundary in various MLT sectors as a function of universal time. White vertical dashed and dotted lines indicate moments of the pressure pulse arrival at the bow shock and its detection at the low-latitude magnetic observatory Bangui, respectively. After the SI, the middle part of the auroral oval was progressing poleward (top panel). Motion of the poleward boundary of the auroral oval (bottom panel) is less prominent.

magnetospheric response to the SI. Below we will discuss this effect, however, the 2-min repetition time of the WIC images makes it difficult to investigate it in detail.

The bottom panel in Fig. 4 shows positions of the poleward boundary of the auroral oval. The motion is less prominent than the motion of the middle of the auroral oval. In particular, at 07:32-07:45 UT we cannot infer a clear poleward motion similar to the motion of the middle of the auroral oval. One can see that in the whole 6-15 MLT sector, the latitude of the poleward boundary increases simultaneously between 07:26 UT and 07:35 UT. To describe this shift quantitatively, we calculated the differences between the PB latitudes before the SI (averaged over 2 images at 07:23-07:26 UT) and after the SI (averaged over 2 images at 07:35-07:38 UT) for all sectors between 06 and 15 MLT. The poleward latitudinal shift in various MLT sectors was between 1.1 and $1.8 \mathrm{deg}$ with $1.5 \pm 0.2^{\circ}$, on average. This shift might be caused by the SI, consistent with Boudouridis et al. (2003), who observed the most prominent decrease in the polar cap size when the solar wind pressure increased under the southward IMF conditions, whereas the smaller response was seen for the IMF $\mathrm{B}_{z}$ near zero. The later observations correspond to our case.

We should note that some motions of the dayside PB can be caused by the IMF variations. At 07:24-07:26 UT (just before the SI arrival to the bow shock) the PB has been shifting equatorward, by $\sim 2-3^{\circ}$ overall. This motion coincideds well with the short-time IMF $\mathrm{B}_{z}$ excursion from the north-

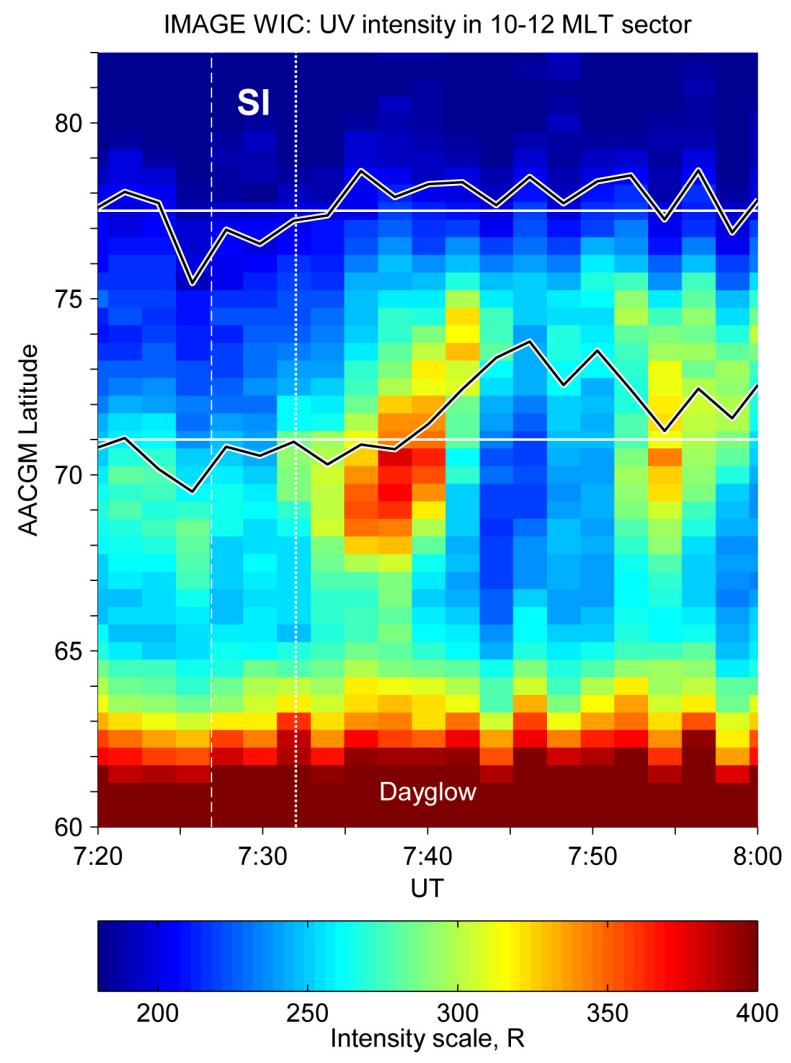

Fig. 5. A "keogram" made from the UV images at about 11 MLT (at the meridian of Svalbard). White vertical dashed and dotted lines indicate the moments of the pressure pulse arrival at the bow shock and its detection at the low-latitude magnetic observatory Bangui, respectively. Black lines indicate the position of the middle and poleward boundaries of the auroral oval. Horizontal white lines at $71^{\circ}$ and $77.5^{\circ}$ of the AACGM latitude indicate the range of latitudes at which the ground-based optical observations were made by a TV all-sky camera at Barentsburg (Svalbard)

ward (about $2.5 \mathrm{nT}$ ) to near-zero (in the ACE data) or even somewhat southward orientation (consider the WIND data, Fig. 2). At the time of the SI occurrence, the IMF $B_{z}$ was returning back to the northward orientation, and this return coincided with the poleward motion of the dayside $\mathrm{PB}$, starting from 07:26 UT. This feature is well seen in Fig. 5, where the latitude of the PB in the 10-12 MLT sector is shown versus UT (in next section this figure will be discussed in more detail). In Fig. 5, the PB was at $\sim 78^{\circ}$ AACGM latitude during the observations, except for an equatorward excursion between 07:25 and 07:35 UT. This excursion corresponded well to the IMF $\mathrm{B}_{z}$ southward excursion at the bow shock between 07:20-07:30 UT (see WIND data in Fig. 2). Since the IMF $\mathrm{B}_{z}$ controls the size of the open polar cap (e.g. Holzworth and Meng, 1984), one can conclude that the short equatorward excursion of the PB at 07:25-07:35 UT was most probably caused by the IMF $B_{z}$ variation.

Because the IMF was changing, both the IMF variations and the solar wind pressure increase might contribute to the poleward motion of the PB at 07:26-07:35 UT. Based on our 


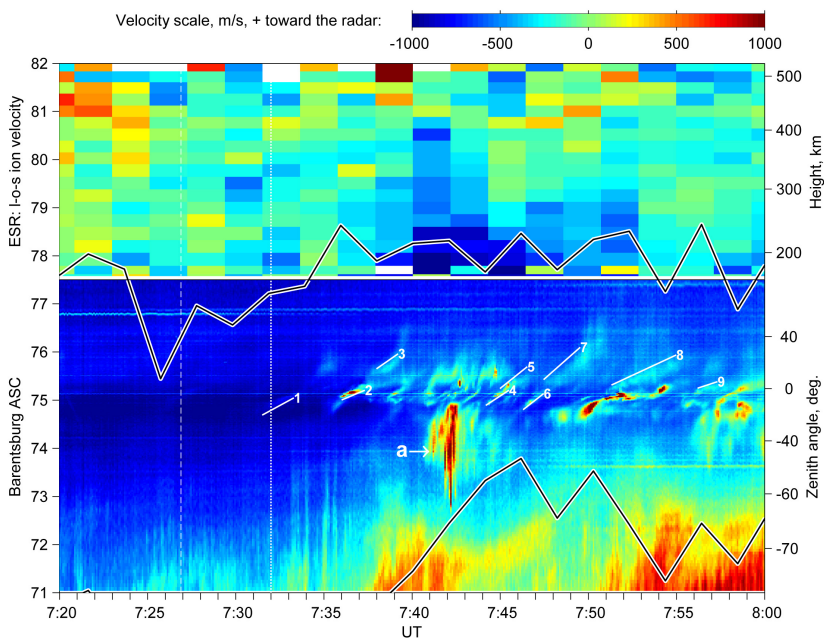

Fig. 6. A keogram from the Barentsburg TV observations (for the same meridian as the UVI data of Fig. 5) and the incoherent scatter radar 1-o-s velocity observed poleward of the TV camera field of view. White vertical dashed and dotted lines indicate the moments of the pulse arrival to the bow shock and its detection at the low-latitude magnetic observatory Bangui, respectively. Black lines indicate the position of the middle part and the poleward boundaries of the auroral oval. Numbers 1-9 and letter "a" label individual auroral forms.

data we cannot to conclude on the main reason for this motion. However, it is remarkable that the PB equatorward excursion was earlier than the prominent poleward motion of the middle of the auroral oval at 07:35-07:45 UT. The obvious conclusion that can be drawn is that this motion of the middle of the auroral oval was not related to variations of the PB location and, hence, was associated with the redistribution of auroras within the auroral oval. In the following discussion we will focus on the motion of the middle of the auroral oval at 07:35-07:45 UT.

\section{Detailed observations near noon}

In this section we compare the satellite data presented above with the ground-based observations made by the ASC and ESR on Svalbard near the local noon (around 11 MLT, see Fig. 3). Details about the optical (ASC BAB) and radar (ESR) operations were given by Kozlovsky et al. (2003), who considered the auroral response to the IMF $\mathrm{B}_{z}$ change earlier on 7 December 2000.

Figure 5, based on the sequence of WIC auroral images, shows the UV luminosity in the 10-12 MLT sector (averaged over longitude) as a function of time and latitude (AACGM). For comparison, black lines show positions of the middle of the auroral oval and the PB at 11 MLT, as they were derived in Sect. 3. The diagram clearly demonstrates a brightness increase and a poleward motion of the auroral oval following the SI. At 07:36-07:44 UT the middle of the auroral oval moved from $70.5^{\circ}$ to $73^{\circ}$. Over this period there were no significant changes in the position of the poleward boundary of the auroral oval.

Horizontal white lines at $71^{\circ}$ and $77.5^{\circ}$ AACGM latitude in Fig. 5 indicate a latitudinal region in which the groundbased optical observations were performed with the ASC (Barentsburg). At the bottom of Fig. 6 we present a keogram obtained from the ASC frames at 5-s resolution. The luminosity height was assumed to be $150 \mathrm{~km}$; this value corresponds to the typical altitude of the lower edge of luminosity for near-noon rayed auroras (Starkov, 1968; Jack and Hallinan, 1994). The keogram was prepared for the direction along the ESR beam, i.e. at $-24^{\circ}$ (northwest) from the geographic meridian; this direction is almost perpendicular to the local L-shells and the auroral oval. Figure 6 uses the same format (UT - AACGM latitude) as Fig. 5, so that one can easily compare the auroral observations made by the IMAGE satellite (in the $71-77.5^{\circ}$ range indicated by the white lines) and the ASC on the ground (the keogram). There is fairly good agreement in the auroral distributions observed by the instruments; this result validates the mapping of the WIC data.

The keogram in Fig. 6 shows that, after the SI, new poleward moving auroral forms develop at AACGM latitudes of $74-76^{\circ}$, the most poleward part of the auroral oval, close to the polar cap boundary. Because of the occurrence of the new luminosity region, the middle of the auroral oval appears to be shifting poleward. Thus, the observed poleward motion of the middle of the auroral oval was associated with changes in the auroral distribution within the auroral oval rather than changes in the poleward boundary of the oval.

The new discrete auroral forms were rayed auroral arcs. Numbers 1-9 on the keogram indicate nine individual auroral forms whose velocities can be reliably inferred from the keogram. There were other auroral forms showing poleward propagation, however they were short-lived or (and) lacked a well-defined low edge, making the velocity determination difficult. In the following, we will compare the velocities of the nine selected auroral forms with the ionospheric plasma drift velocity measured by the ESR radar. The ESR radar observed plasma flows at $\mathrm{F}$ region heights (between 200 and $500 \mathrm{~km}$, antenna elevation angle to the horizon was $30^{\circ}$ ) at latitudes of $77.5-82^{\circ}$, just poleward of the keogram region. The measured l-o-s velocity at various ACCGM latitudes is presented as a function of time on the top panel of Fig. 6. The radar was looking along the azimuth of $-24^{\circ}$, which is the keogram line, so that the ionospheric plasma velocity component along this direction can be derived accurately. Under the assumption of zero field-aligned ion velocity, we calculated the average plasma drift velocity over the height range of $200-300 \mathrm{~km}$. This height range corresponds to the $78-79^{\circ}$ latitudinal region that is poleward of the observed auroras by $3-4^{\circ}$. Since the drift velocity measured at some distance from the discrete auroral forms is usually not strongly affected by small-scale changes associated with auroral rays, one may consider the measured velocities as representing large-scale plasma convection in the region of optical observations. 
In Fig. 7, solid lines present the plasma drift velocity. Dashed lines show the range of the velocity error in measurements; this value includes the measurement errors and the uncertainty due to an unknown field-aligned component. Figure 7 demonstrates that the SI was followed by an increase in the northward plasma drift velocity from $0-100 \mathrm{~m} / \mathrm{s}$ to $400-700 \mathrm{~m} / \mathrm{s}$. The peak value of $700 \mathrm{~m} / \mathrm{s}$ was observed about $10 \mathrm{~min}$ after the low-latitude magnetic disturbance was detected.

Gray rectangles with numbers in Fig. 7 represent the velocities (with errors) of corresponding auroras indicated in Fig. 6. These auroras were moving northward along the ESR beam (i.e. across the L-shell) with velocities that were close to the ionospheric plasma drift velocity in the same direction. From the presented information, two quite different conclusions could be made. The first one is that the auroral forms were stretched along the L-shell direction (or not moving along the L-shells) and drifted northward with the ambient plasma. The second possible conclusion is that the auroral forms were oriented at some angle to the L-shells and had apparent north-south velocities due to actual motion in the east-west direction; however, the north-south velocities of all nine arcs were accidentally close to the velocity of the plasma drift in the same direction. Obviously, the first statement is much more likely to be correct than the second one. Indeed, it has long been known that auroral arcs tend to orient along the L-shells. Thus, we have concluded that the auroras were moving northward with velocities close to the ionospheric plasma drift velocity in the same direction. This conclusion would have been proved to be better substantiated if one determined the orientation of the auroras from the ASC frames. However, it was very difficult to determine the orientation of the rayed arcs, since they were observed close to the zenith of the ASC.

\section{Interpretation and discussion}

Our observations of the solar wind pressure effects can be summarized as follows. A solar wind pressure increase causes brightening of the dayside auroral oval, and enhancement of the poleward plasma flow in the dayside ionosphere. New discrete auroral forms appear at the poleward part of the auroral oval so that the middle of the dayside oval appears to be shifting poleward from about $70^{\circ}$ to about $73^{\circ}$ of AACGM latitude. The shift occurs first in the local time sector of the pressure pulse hit of the magnetosphere (15 MLT) and then similar motions are seen in later MLT sectors, so that the disturbance "propagates" to the west with a velocity of $\sim 7 \mathrm{~km} / \mathrm{s}$ at the ionospheric level. This poleward motion of the middle of the auroral oval was caused by a redistribution of luminosity within the auroral oval and was not associated with motion of the poleward boundary of the auroral oval. The new individual auroral forms move poleward with the velocity of the ionospheric plasma convection. Below we propose a qualitative model that explains this sequence of events.

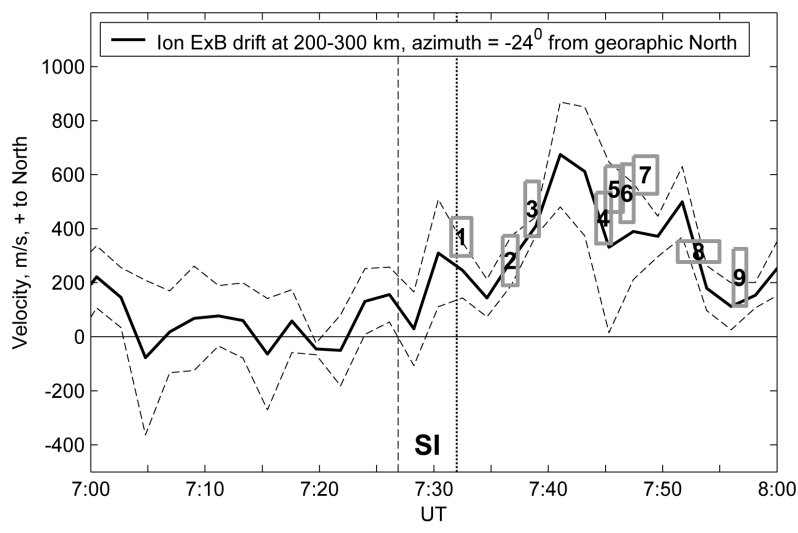

Fig. 7. Velocities of the poleward progression of the auroral forms and the plasma drift measured by the ESR radar between 07:00 UT and 08:00 UT. Vertical dashed and dotted lines indicate the times of the pulse arrival at the bow shock and its detection at the lowlatitude magnetic observatory Bangui, respectively. Gray rectangles with numbers show the velocity and its error bar for the auroras indicated in Fig. 6.

\subsection{Magnetospheric propagation of the SI disturbance}

First, we would like to note that the westward velocity of $\sim 7 \mathrm{~km} / \mathrm{s}$ in the ionosphere corresponds to $\sim 200 \mathrm{~km} / \mathrm{s}$ in the vicinity of the magnetopause (at $10 \mathrm{R}_{E}$ ). This is a typical value for the plasma flows observed in the magnetosheath (Phan et al., 1994). One can suggest that the motion of the auroral oval was caused by the solar wind pressure disturbance propagating along the magnetopause away from the 15 MLT sector. Each point at the magnetopause, to which the disturbance arrives, becomes a source of spherical magnetosonic (fast Alfvén mode) waves. These waves propagate in the magnetosphere at a typical speed of the order of $1000 \mathrm{~km} / \mathrm{s}$ (Alfvén speed), with amplitudes decreasing as an inverse square distance from the sources. At each point, a resultant perturbation of the magnetospheric magnetic field is a superposition of all waves reaching this point by the time of interest. For each moment, one can indicate a boundary separating the part of the magnetosphere where the magnetic field has already increased significantly from the rest of the magnetosphere where the change has not yet become large. This boundary, referred to below as the SI pressure front, propagates anti-sunward from the magnetopause, at the velocity of the same order as the magnetosheath plasma flow, i.e. about $200 \mathrm{~km} / \mathrm{s}$. We stress the difference between the front of a magnetosonic wave (propagating at the Alfvén speed) and the slower SI pressure front (which is formed by the sum of many magnetosonic waves). Such slow propagation of the front is consistent with observations by Zhou and Tsurutani (1999), who reported the SI-caused intensification of dayside high-latitude auroras which propagated both west and east with a speed of 6 to $11 \mathrm{~km} / \mathrm{s}$. This is close to what we found in this study. The fast Alfvén wave may also produce auroral intensification; this effect will be discussed later in Sect. 5.3. 

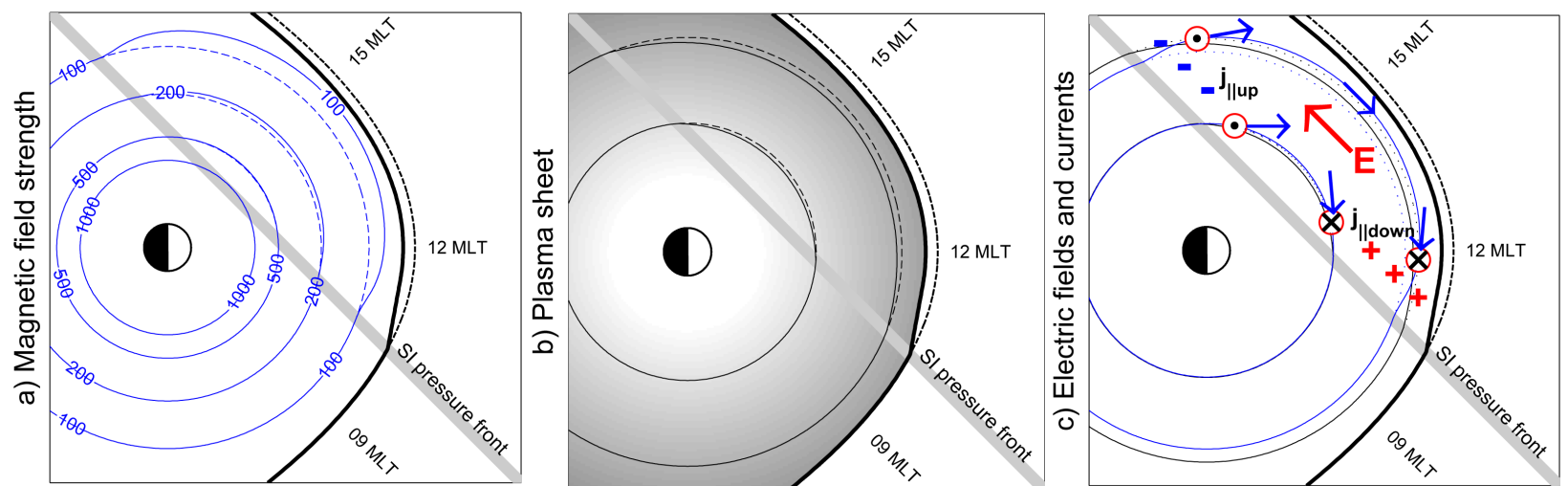

Fig. 8. Sketches showing propagation of the pressure disturbance in the equatorial plane of the magnetosphere and generation of the eastward electric field. Thick gray line represents the pressure front approaching the Earth in the 15 MLT sector. (a) The pulse-related magnetic field intensity distribution. Behind the pressure front, the magnetic field is increased so that the contours of constant magnetic field (blue lines) shift away from the Earth, from the positions indicated by dashed lines to the new positions shown by solid lines. (b) Distribution of the hot magnetospheric plasma density. The plasma, together with the magnetic flux tubes, moves toward the Earth in the equatorial plane because of the induced electric field. This results in the magnetospheric plasma boundaries' (e.g. indicated by black contour lines) motion toward the Earth, from the positions indicated by dashed lines to the new positions shown by solid lines. (c) The magnetic field intensity contours and the plasma boundaries move in the opposite directions. As the contours move, the angle between the plasma boundaries (black contours) and the $B=$ const lines (blue contours) changes. In those parts of the space where the $B=$ const contours cross the plasma boundaries, polarization electric charges, electric fields, and field-aligned currents are generated with the directions as indicated on the diagram.

In some way, the compressing SI generates a potential (i.e. curl-free, $\nabla \times \boldsymbol{E}=0$ ) eastward electric field behind the front. Contrary to the induced westward electric field Eq. (1), the potential electric field is transmitted along magnetic field lines from the magnetosphere to the ionosphere. This electric field drives the $\boldsymbol{E} \times \boldsymbol{B}$ drift of the magnetic flux tubes within the auroral oval, and this drift is also observed as the poleward motion of the auroral forms. In the following section, we consider the generation of the electric field.

\subsection{Generation of the ionospheric plasma flow}

It has been long known that the SI generates a twin-vortex plasma flow pattern on the dayside, with a pair of up- and downward field-aligned currents (FAC) in the post- and prenoon centers of the vortices, respectively, and the poleward flow (caused by eastward electric field) between them (Araki, 1994). Such electric field and FAC patterns were also demonstrated by numerical MHD simulations (Slinker et al., 1999; Keller et al., 2002). Physics of these FACs and electric fields can be explained on the basis of the analytical model developed by Kozlovsky et al. (1994) and Kozlovsky and Lyatsky (1995). These authors investigated a quasi-steadystate compression of the magnetosphere and showed that the compression modifies the large-scale field-aligned currents driven by the plasma pressure gradients. The shape and magnitude of the FAC changes are similar to a typical SIassociated disturbance. In the following, we interpret our observations based on the ideas of Kozlovsky et al. (1994).

Sketches in Fig. 8 show the propagation of the SI front in the equatorial plane of the magnetosphere. Thick gray lines represent the pressure front propagating from the 15 MLT sector. Contour lines in Fig. 8a show a typical strength of the magnetic field. Behind the pressure front, the magnetic field is increased. Hence, the contours of constant magnetic field ( $B=$ const contours) move away from the Earth, from the positions indicated by the dashed lines, to the new positions shown by the solid lines. Note that this motion of the contour lines is not the motion of the magnetic flux tubes. On the contrary, the magnetic flux tubes (i.e. the magnetospheric plasma) being driven by the induced electric field Eq. (1), move toward the Earth (in the equatorial plane). Note that this motion is not mapped into the ionosphere, as it was explained earlier. Hence, the magnetospheric plasma boundaries move toward the Earth, as illustrated in the middle panel (contour lines in Fig. 8b). In our discussion here, the plasma boundaries are the surfaces separating the plasma regions with different characteristics (such as temperature, density, pressure, etc.). It is important to realize that the magnetic field contours and the plasma boundaries move in opposite directions, as shown in Figs. 8a and b, and, hence, the angle between the plasma boundaries and the $B=$ const contours is changed behind the propagating front.

Due to the gradient of the magnetic field strength and the field line curvature, hot plasmasheet particles drift around the Earth, producing the westward ring electric current (gradient drift current). In a simple case, for example, for the dipolelike magnetic field, the gradient drift current flows along the $B=$ const contours. On the other hand, the intensity of this current depends on the plasma characteristics (temperature and density). Hence, when the $B=$ const contours cross the plasma boundaries, polarization electric charges, electric fields, and field-aligned currents are generated, as shown in 
Fig. 8c. Magnitudes of the electric field and FACs depend on the angle between the $B=$ const contours and the plasma boundaries, so that the changes produced by the SI result in electric field and FAC changes. Being generated by the electric charge separation, this electric field is mapped onto the ionosphere where corresponding plasma drift is observed. This simple qualitative explanation allows us to understand why the SI can generate the plasma flow; however, one needs a quantitative approach to estimate the direction and value of the plasma velocity.

The field-aligned currents can be calculated as (Vasyliunas, 1970)

$j_{\|}=V^{-\gamma}\left(\boldsymbol{e}_{z} \cdot\left[\nabla V \times \nabla\left(p V^{\gamma}\right)\right]\right)$,

where $p$ is the plasma pressure, $\boldsymbol{e}_{z}$ is the unit vector directed along the magnetic field, and $\gamma$ is the ratio of specific heats. The differential flux tube volume $V$ (i.e. a volume of magnetic flux tube with unit magnetic flux) is given by

$V=\int \frac{d l}{B}$,

where the integration is to be done along the magnetic field lines from the equatorial plane to the ionosphere. Equation (6) is valid in a steady-state case, i.e. when changes in the flux tubes are slower than the Alfvén wave bouncing between the hemispheres. Since the bounce time is about $2 \mathrm{~min}$ whereas the SI propagation through the dayside magnetosphere took 13 min (07:32-07:45 UT), Eq. (6) can be used in our case.

If one assumes slow flow and no particle loss, then the frozen-in-flux condition implies that the pressure invariant $p V^{\gamma}(\gamma=5 / 3)$ is constant along a fluid flow path. The boundaries separating plasmas of different $p V^{\gamma}$ correspond to the magnetospheric plasma boundaries that we discussed above. Many studies have shown that the value of $p V^{\gamma}$ increases with the distance away from the Earth (Borovsky et al., 1998; Garner et al., 2003, and references therein), and we indicate this effect by gray scaling in Fig. 8b. As long as the most contribution to Eq. (7) comes from the equatorial plane, the $V=$ const contours are practically aligned with the $B=$ const contours in Fig. 8, and the flux tube volume increases with the distance from the Earth (in some sense, the whole nearEarth plasma sheet can be considered as a smooth broad plasma boundary). The electric field and FAC behind the SI front are determined by the angle between the two gradients, $\nabla V$ and $\nabla\left(p V^{\gamma}\right)$, as follows from Eq. (6). As Fig. 8c demonstrates, the compressing SI generates an eastward electric field behind the front. This electric field drives the $\boldsymbol{E} \times \boldsymbol{B}$ drift of the magnetic flux tubes within the auroral oval, which is also observed as the drift motion of auroral forms. It does not lead to motion of the poleward boundary of the auroral oval because the PB motion is controlled by the reconnection processes rather than the electric fields generated in the closed magnetosphere.

A quantitative relationship between the magnetospheric magnetic disturbance ( $\boldsymbol{B}_{C F}$ in Eq. (1)) and the high-latitude magnetic disturbance on the Earth's surface (produced by the
Hall ionospheric current associated with the potential electric field) is of the order of 1:6, as was shown by Kozlovsky and Lyatsky (1995). In our case, the low-latitude magnetic disturbance on the ground was $\sim 20 \mathrm{nT}$ (Fig. 2, middle panel). Half of the value should be attributed to the effects of the currents induced in the conducting Earth. Hence, the magnitude of $\boldsymbol{B}_{C F}$ was of the order of $10 \mathrm{nT}$. In the dark ionosphere, a typical Hall ionospheric conductance is about 2 mho. Hence, the model predicts the ionospheric electric field and drift velocity values of the order of $25 \mathrm{mV} / \mathrm{m}$ and $500 \mathrm{~m} / \mathrm{s}$, respectively. This is consistent with the observed drift velocities (Fig. 7).

The model in Fig. 8 implies a convection vortex propagating westward from the 15 MLT sector. Such a vortex should be seen in the data of the Super Dual Auroral Radar Network (SuperDARN) radars. The SuperDARN is a network of high-frequency (HF) coherent radars providing measurements of the ionospheric plasma drift in a significant portion of the high-latitude ionosphere. In the Northern Hemisphere, the radars cover magnetic latitudes of $65^{\circ}-85^{\circ}$ and more than half of the globe in longitude. A detailed description of the system was given by Greenwald et al. (1995). The SuperDARN radars are sensitive to $F$-region electron density irregularities with scale sizes of $10-15 \mathrm{~m}$. At $F$-region heights, such irregularities move with the convection velocity $(\boldsymbol{E} \times \boldsymbol{B}$ drift) so that the Doppler shift of the received signal is the line-of-sight component of the convection velocity. By combining the measurements from all radars, a global scale convection map can be obtained. In the present study, we consider data from six radars located in Canada (Saskatoon, Kapuskasing, and Goose Bay), Iceland (Stokkseyri and Pykkvybaer), and Finland (Hankasalmi). The radars are positioned along $\sim 60^{\circ}$ geomagnetic latitude in the longitudinal range from $47^{\circ} \mathrm{W}$ to $103^{\circ} \mathrm{E}$ (AACGM). Imaging the largescale convection has been done using the fitting technique described by Ruohoniemi and Baker (1998). This method derives large-scale convection maps based on all available 1o-s velocity data obtained from the SuperDARN radars. We investigated a sequence of the SuperDARN global convection patterns averaged over $2 \mathrm{~min}$ for the time interval 07:3007:46 UT, when the SI disturbance was propagating through the dayside magnetosphere. The background convection pattern averaged over 10 min (at 07:20-07:20 UT, just before the SI impact) was subtracted from each pattern of the sequence, so that the residual sequence (Fig. 9) represents development of the convection disturbance launched by the SI. Blue lines indicate the position of the middle of the auroral oval, with the vectors showing direction and apparent velocity of the poleward shift of the oval at every moment. Red circles represent the convection vortex expected in front of the propagating disturbance. There is a lack of vectors in the region of interest (the HF radar returns are hardly possible from regions of intense auroras), and one should keep in mind that the presented SuperDARN patterns are smoothed in both space and time. However, Fig. 9 demonstrates a good qualitative agreement between the SuperDARN data and the model prediction, in a sense of the rotation and position of the vortex, at the very least. 

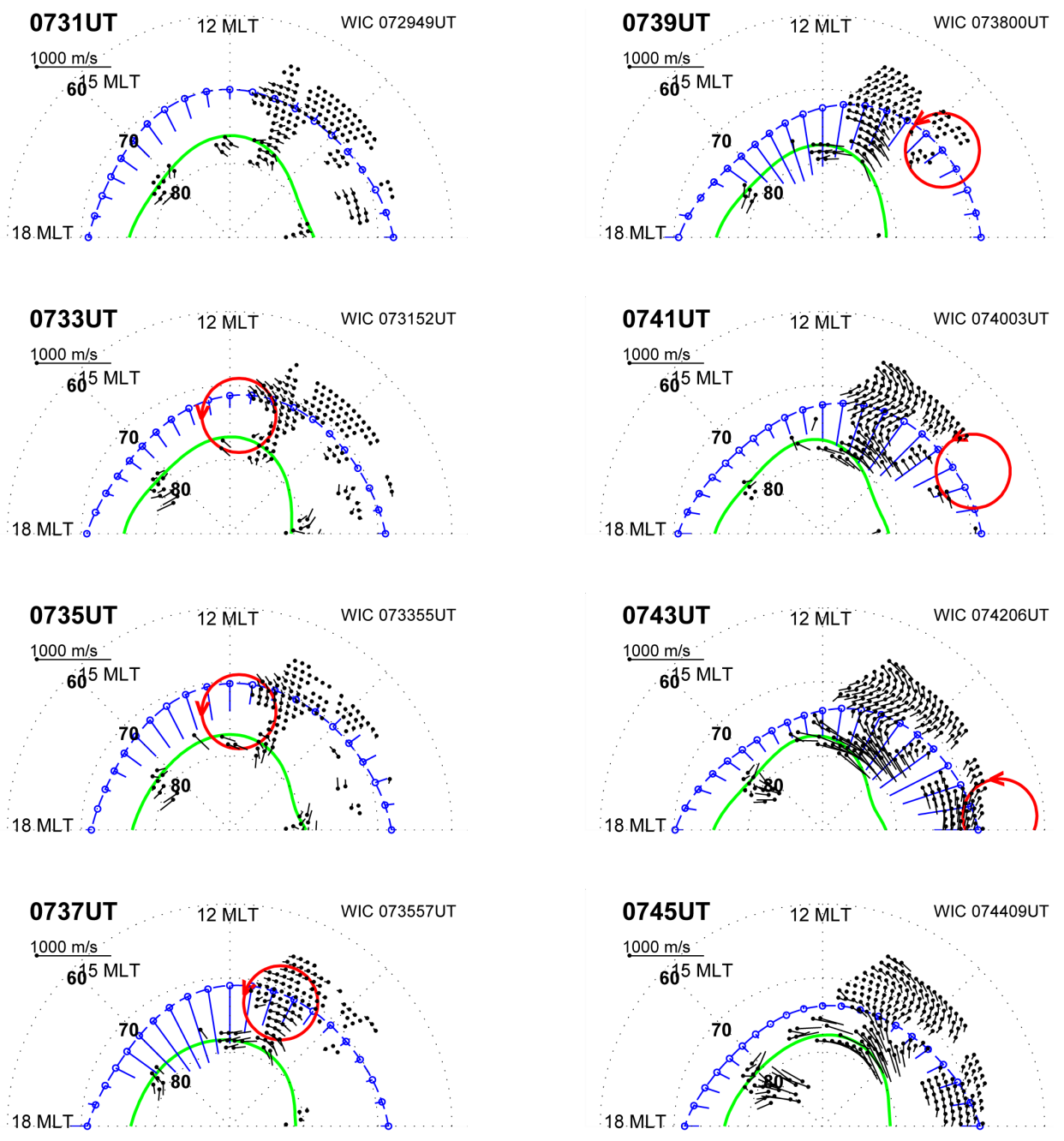

Fig. 9. A sequence of residual SuperDARN convection patterns illustrating the convection disturbance launched by the sudden impulse. Blue lines indicate the position of the middle part of the auroral oval, and the vectors show the direction and apparent velocity of the poleward shift of the oval at that moment. Red circles represent the convection vortex expected to be present in front of the propagating disturbance. Green line shows the poleward boundary of the auroral oval.

To summarize this section, the proposed model implies that the SI pressure disturbance changes the magnetospheric magnetic field and the distribution of hot magnetospheric plasma in such way that a pair of field-aligned currents and a potential electric field are generated behind the propagating front. The electric field causes poleward drift of plasma and auroras, which was observed in the dayside auroral ionosphere. The model is consistent with the presented observations, including the value of the poleward velocity.

\subsection{Mechanisms for auroral structures}

In this section we would like to make some remarks concerning mechanisms for generation of the auroral forms caused by a SI.

In the magnetosphere, the compression energy of the solar wind can be transformed into the Alfvén shear toroidal oscillations, which are the eigenmode or field line resonance (FLR) oscillations (e.g. Hughes, 1994; Samson and Rankin,
1994 and references therein). These oscillations are associated with radial electric field and azimuthal motion of the magnetospheric plasma. At high latitudes they produce an effect in the $H$-component of the magnetic field measured on the ground. Figure 10 shows such FLR magnetic pulsations excited by the SI in our case. The period of the FLR increases with latitude, so even, if the FLR were excited with the same phase at all L-shells (at 07:35 UT), the phase difference between oscillations of neighboring L-shells would appear later. At 07:42 UT, the magnetic disturbance at LYR was positive, which indicates an eastward ionospheric Hall current and, hence westward plasma flow. At lower latitude (BJN) the flow was in the opposite direction. Hence, a flow shear existed at latitudes of the HOR station, and this is close to the latitude where the bright auroral form (indicated by letter "a" in Fig. 6) occurred. The flow shear can launch the Kelvin-Helmholtz $(\mathrm{K}-\mathrm{H})$ instability, which can produce plasma irregularities giving rise to the auroral arcs. Hence, 
the aurora "a" could be generated due to the phase difference between the FLR oscillations on neighboring L-shells. A similar model for the dayside auroras generation through the FLR was considered by Kozlovsky and Kangas (2002).

If the angle between the two gradients in Eq. (6) is nonzero (i.e. if $\nabla p \times \nabla V \neq 0$ ), the plasma boundary (i.e. the region where $\left.\nabla\left(p V^{\gamma}\right) \neq 0\right)$ is unstable with respect to the interchange instability (e.g. Volkov and Maltsev, 1986; Kozlovsky and Lyatsky, 1994; Kozlovsky et al., 2003), the larger the angle, the larger the instability growth rate. The instability splits the plasma boundary into small-scale tonguelike structures, which give rise to the discrete auroras forming the bright auroral oval. The pressure gradient existing in the plasma sheet gains the normal component to $\nabla V$ in the course of the magnetosphere compression by the SI, as was explained above. Then, the interchange instability causes discrete auroras that are seen as a brightening of the dayside auroral oval. These discrete auroras occur on closed magnetic field lines and move poleward following the drift of magnetic flux tubes. Auroral forms 1-9 in Figs. 6 occurred after the SI, and they propagated poleward with the plasma convection velocity (see Fig. 7), so that they (or some of them) might be generated due to the interchange instability. The FLR oscillations (Fig. 9) suggest closed magnetic field lines, however, particle precipitation data from low-altitude satellites would be desirable to confirm this expectation. A more detailed discussion of the dayside auroras generation by the interchange instability and comparison with other mechanisms can be found in Kozlovsky et al. (2003).

Finally, one should discuss our results in light of other recent studies, in which global ultraviolet satellite images were used to investigate the response of the auroral intensity to solar wind pressure changes (Zhou and Tsurutani, 1999; Boudouridis et al., 2003; Meurant et al., 2003). Two types of the auroral response were observed. The first type, "fast response", was seen as a nearly simultaneous (within 2 min after SI) intensification of the whole auroral oval (e.g. Boudouridis et al., 2003). In this case, the precipitation increase was probably launched by the fast Alfvén (magnetoacoustic) waves propagating across magnetic flux tubes (e.g. Meurant et al., 2003 and references therein). The motion of the entire auroral oval at 08:32-08:36 UT mentioned in Sect. 3 might be a signature of the "fast response". The second type, "slower response", was seen as the auroral brightening propagating from noon to both west and east with a speed of 6 to $11 \mathrm{~km} / \mathrm{s}$ (Zhou and Tsurutani, 1999). The westward propagating disturbance at 08:32-08:45 UT considered in the present study belongs to this type. To explain the "slower response", Zhou and Tsurutani (1999) suggested that the magnetospheric compression leads to the loss cone instability, wave-particle interaction and the precipitation increase, i.e. basically the same precipitation mechanism that was suggested for the "fast response" precipitation. The loss-cone scattering should produce diffuse precipitations. We have shown that "the slower response" is also associated with generation of new auroral structures. This means an increase in the total precipitation power in the auro-

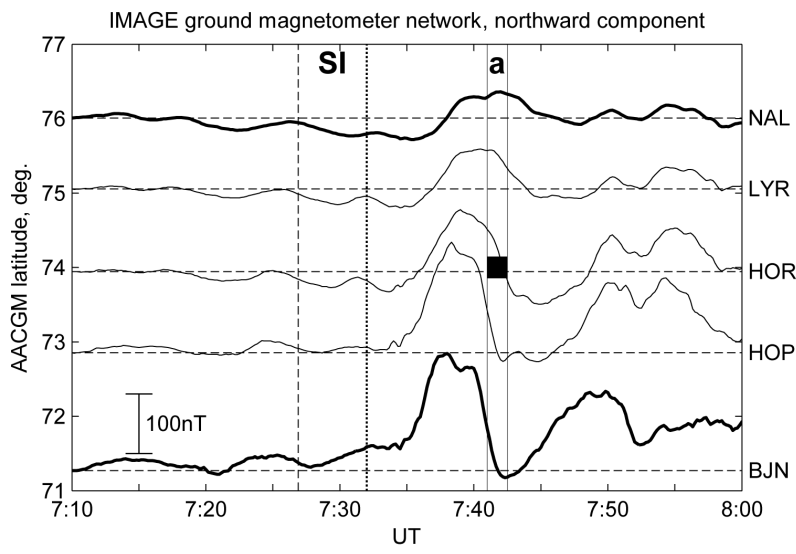

Fig. 10. Magnetic disturbances ( $H$-component) according to the IMAGE magnetometer network around Svalbard between 07:10 UT and 08:00 UT. Vertical dashed and dotted lines indicate the moments of the pulse arrival at the bow shock and its detection at the low-latitude magnetic observatory Bangui, respectively. Auroral form "a" (see Fig. 6) was observed at latitudes of a change in the sign of the magnetic disturbance (+ in LYR and - in HOP), indicating a shear in the $\mathrm{E}-\mathrm{W}$ plasma flow.

ral oval, however, the structured precipitations are probably associated with field-aligned acceleration rather than with loss-cone scattering. We think that both diffuse and structured precipitation can contribute to auroral intensification for "slower response" events. Boudouridis et al. (2003) concluded that the preconditioning of the magnetosphere plays an important role in the type of response observed: a long interval of pre-existing southward IMF induces the "fast response", whereas near-zero or northward IMF $B_{z}$ could lead to a more gradual "slower response". We observed a prominent "slower response" during dominating northward IMF conditions, which agrees with the conclusion of Boudouridis et al. (2003). The model proposed in this study implies dependence on the pre-existing state of the magnetosphere, however, additional data on the magnetospheric plasma distribution would be necessary for further progress in this issue.

\section{Summary}

In this study we used global ultraviolet auroral images from the IMAGE satellite to investigate the dynamics of the dayside auroral oval response to the solar wind dynamic pressure increase which occurred under northward IMF conditions on 7 December 2000. TV all-sky camera observations concurrent with the satellite measurements allowed us to investigate the response of high-latitude auroral forms on a finer scale. The EISCAT radar monitoring ionospheric plasma flows at Svalbard in the 11 MLT sector allowed us to investigate the motion of the auroras with respect to ionospheric plasma convection. 
The IMAGE observations showed that:

1. After the SI, the middle of the dayside auroral oval moved poleward from about $70^{\circ}$ to about $73^{\circ}$ AACGM latitude. This poleward motion was first seen in the 15 MLT sector, later it occurred in the MLT sectors located more westerly, and finally, it reached the 6 MLT sector. Thus, the auroral disturbance was propagating westward, from 15 to 6 MLT, at a velocity of the order of $7 \mathrm{~km} / \mathrm{s}$.

2. This motion of the middle of the auroral oval was caused by the redistribution of the luminosity within the auroral oval and was not accompanied by the corresponding motion of the poleward boundary of the auroral oval.

3. Within $10 \mathrm{~min}$ after the SI arrival to the bow shock (before the poleward shift of the middle of the auroral oval), the poleward boundary of the auroral oval in the dayside (6-15 MLT) sector moved poleward by about $2^{\circ}$. This motion might be caused by the SI or (and) by the IMF $\mathrm{B}_{z}$ variation occurring just before the SI.

Detailed observations near Svalbard (at $\sim 11$ MLT) showed that:

1. The solar wind pressure increase caused a brightening of the dayside auroral oval, and poleward moving auroral forms (rayed arcs) developed in the pre-noon sector at $74-76^{\circ}$ AACGM latitude, which was in the most poleward region of the auroral oval, close to the polar cap boundary.

2. The SI was followed by an increase in the northward plasma drift velocity from $0-100 \mathrm{~m} / \mathrm{s}$ to $400-700 \mathrm{~m} / \mathrm{s}$. A peak value of $700 \mathrm{~m} / \mathrm{s}$ was observed about $10 \mathrm{~min}$ after the detection of SI-related magnetic disturbances at the very low-latitude magnetic station Bangui.

3. The individual auroral forms moved poleward with the speed of the northward plasma drift.

On the basis of the observations we proposed a scenario of physical processes occurring in the magnetosphere and ionosphere after the SI.

1. We suggested that the solar wind dynamic pressure disturbance propagates along the magnetopause away from the 15 MLT sector where the SI encountered the magnetosphere. Each point at the magnetopause to which the disturbance arrived becomes a source of spherical magnetosonic (fast Alfvén mode) waves. In the magnetosphere, a total disturbance of the magnetospheric magnetic field results from a superposition of all waves reaching this point by the time of interest. In each moment, one can indicate a boundary separating the part of the magnetosphere where the magnetic field has already increased significantly, from the rest of the magnetosphere where the changes have not yet become large. This boundary (referred to as the SI pressure front) propagates anti-sunward from the dayside magnetopause, at a velocity of the same order of magnitude as the magnetosheath plasma flow, i.e. about $200 \mathrm{~km} / \mathrm{s}$. We emphasize the difference between the front of a magnetosonic wave (propagating at the Alfvén speed of the order of $1000 \mathrm{~km} / \mathrm{s}$ ) and the SI pressure front (which is formed by a sum of many magnetosonic waves and propagates at the velocity of about $200 \mathrm{~km} / \mathrm{s}$ ).

2. Behind the pressure front, the magnetic field increases so that the contours of constant magnetic field ( $B=$ const contours) move away from the Earth. On the contrary, the magnetospheric plasma moves toward the Earth. Hence, the propagating SI changes the angle between the plasma boundaries and the $B=$ const contours, which leads to a pair of field-aligned currents and a potential (curl-free) electric field generation behind the propagating front. The electric field causes poleward plasma drift on closed magnetic field lines, but it does not cause motion of the boundary between the open and closed field lines. The model is very consistent with presented observations, including the value of the poleward velocity, and finds a support in the global convection maps obtained from the SuperDARN HF radars.

3 . We suggest that a solar wind pressure pulse can produce auroral arcs in the poleward part of the auroral oval in two ways. The arcs can be generated due to the phase difference between the FLR oscillations on neighboring L-shells excited by the SI and corresponding shear flow. The other possible mechanism is the interchange instability developing due to the magnetospheric re-configuration caused by the SI.

4. Because the new discrete auroral forms appear in the poleward part of the auroral oval, the middle of the oval appears to be shifting poleward. Thus, the apparent poleward motion of the middle of the auroral oval is associated with the changes in luminosity distribution within the auroral oval.

Acknowledgements. We are indebted to the Director and staff of EISCAT for operating the facility and supplying the data. EISCAT is an International Association supported by Finland (SA), France (CNRS), the Federal Republic of Germany (MPG), Japan (NIPR), Norway (NFR), Sweden (NFR), and the United Kingdom (PPARC). The IMAGE data were made available by NASA through SwRI subcontract number 83820 at UC Berkeley under contract number NAS5-96020. We thank all participants of the SuperDARN projects who collected data used in this study. We thank the Coordinated Data Analysis Web (CDAWeb) and the data providers R. Lepping (NASA/GSFC) for the Wind magnetic field data, K. Ogilvie (NASA GSFC) for the Wind solar wind data, and N. Ness (Bartol Research Institute) for the ACE magnetic field data. We thank the Finnish Meteorological Institute and other institutes who maintain the IMAGE magnetometer array. Data of the magnetic observatory Bangui were obtained through the SPIDR data system. The study was supported by the Academy of Finland and NSERC (Canada).

Topical Editor T. Pulkkinen thanks D. Lummerheim and another referee for their help in evaluating this paper. 


\section{References}

Araki, T.: A physical model of the geomagnetic sudden commencement, in: Solar Wind Sources of Magnetospheric Ultra-LowFrequency Waves, Geophys. Monogr. Ser., 81, 183-200, AGU, Washington, D.C., 1994.

Baker, J. B., Clauer, C. R., Ridley, A. J., Papitashvili, V. O., Brittnacher, M. J., and Newell, P. T.: The nightside poleward boundary of the auroral oval as seen by DMSP and the Ultraviolet Imager, J. Geophys. Res., 105, 21 267-21 280, 2000.

Borovsky, J. E., Thomsen, M. F., Elphic, R. C., Cayton, T. E., and McComas, D. J.: The transport of plasma sheet material from the distant tail to geosynchronous orbit, J. Geophys. Res., 103, 20 297-20332, 1998.

Boudouridis, A., Zesta, E., Lyons, R., Anderson, P. C., and Lummerzheim, D.: Effect of solar wind pressure pulses on the size and strength of the auroral oval, J. Geophys. Res., 108(A4), 8012, doi: 10.1029/2002JA009373, 2003.

Brittnacher, M., Fillingim, M., Parks, G., Germany, G., and Spann, J.: Polar cap area and boundary motion during substorms, J. Geophys. Res., 104, 12 251-12 262, 1999.

Brittnacher, M., Wilber, M., Fillingim, M., Chua, D., Parks, G., Spann, J., and Germany, G.: Global auroral response to a solar wind pressure pulse, Adv. Space Res., 25, 1377-1385, 2000.

Garner, T. W., Wolf, R. A., Spiro, R. W., Thomsen, M. F., and Korth, H.: Pressure balance inconsistency exhibited in a statistical model of magnetospheric plasma, J. Geophys. Res., 108(A8), 1331, doi: 10.1029/2003JA009877, 2003.

Greenwald, R. A., Baker, K. B., Dudeney, J. R., Pinnock, M., Jones, T. B., Thomas, E. C., Villain, J.-P., Cerisier, J.-C., Senior, C., Hanuise, C., Hunsucker, R. D., Sofko, G., Koehler, J., Nielsen, E., Pellinen, R., Walker, A. D. M., Sato, N., and Yamagishi, H.: DARN/SuperDARN: A global view of high-latitude convection, Space Sci. Rev., 71, 763-796, 1995.

Holzworth, R. H. and Meng, C.-I.: Auroral boundary variations and the interplanetary magnetic field, Planet. Space Sci., 32, 25-29, 1984.

Hughes, W. J.: Magnetospheric ULF waves: A tutorial with a historical perspective, in Solar Wind Sources of Magnetospheric Ultra-Low-Frequency Waves, Geophys. Monogr. Ser., 81, 1-11, AGU, Washington, D.C., 1994.

Jack, T. M. and Hallinan, T. J.: Measurement of auroral rays from the space shuttle, J. Geophys. Res., 99, 8865-8872, 1994.

Keller, K. A., Hesse, M., Kuznetsova, M., Rastätter, L., Moretto, T., Gombosi, T. I., and DeZeeuw, D. L.: Global MHD modeling of the impact of a solar wind pressure change, J. Geophys. Res., 107(A7), 1126, doi: 10.1029/2001JA000060, 2002.

Kozlovsky, A. and Kangas, J.: Motion and origin of noon highlatitude poleward moving auroral arcs on closed magnetic field lines, J. Geophys. Res., 107, 1017, doi:10.1029/2001JA900145, 2002.

Kozlovsky, A. E. and Lyatsky, W. B.: Instability of the magnetosphere-ionosphere convection and formation of auroral arcs, Ann. Geophys., 12, 636-641, 1994,

\section{SRef-ID: 1432-0576/ag/1994-12-636.}

Kozlovsky, A. E. and Lyatsky, W. B.: Reply to Yu. P. Maltsev's Commens on "The transformation of magnetoacoustic waves into Alfvén waves inside the magnetosphere" by Kozlovsky, A. E., V. V. Safargaleev and W. B. Lyatsky, Ann. Geophys., 13, 1125-1126, 1995.

Kozlovsky, A. E., Safargaleev, V. V., and Lyatsky, W. B.: The transformation of magnetoacoustic waves into Alfvén waves inside the magnetosphere, Ann. Geophys., 12, 1022-1026, 1994, SRef-ID: 1432-0576/ag/1994-12-1022.

Kozlovsky A., Safargaleev, V., Jussila, J., and Koustov, A.: Prenoon high-latitude auroral arcs as a manifestation of the interchange instability, Ann. Geophys., 21, 2303-2314, 2003,

SRef-ID: 1432-0576/ag/2003-21-2303.

Mende, S. B., Heetderks, H., Frey, H. U., Lampton, M., Geller, S. P., Habraken, S., Renotte, E., Jamar, C., Rochus, P., Spann, J., Fuselier, S. A., Gerard, J.-C., Gladstone, R., Murphree, S., and Cogger, L.: Far ultraviolet imaging from the IMAGE spacecraft. 1. System design, Space Sci. Rev., 91, 243-270, 2000a.

Mende, S. B., Heetderks, H., Frey, H. U., Lampton, M., Geller, S. P., Abiad, R., Siegmund, O. H. W., Tremsin, A. S., Spann, J., Dougani, H., Fuselier, S. A., Magoncelli, A. L., Bumala, M. B., Murphree, S., and Trondsen, T.: Far ultraviolet imaging from the IMAGE spacecraft. 2. Wideband FUV imaging, Space Sci. Rev., 91(1-2): 271-285, 2000b.

Meurant, M., J.-C. Gérard, B. Hubert, C. Blockx, N. Østgaard, and S. B. Mende: Dynamics of global scale electron and proton precipitation induced by a solar wind pressure pulse, Geophys. Res. Lett., 30(20), 2032, doi: 10.1029/2003GL018017, 2003.

Phan, T.-D., Paschmann, G., Baumjohann, W., Sckopke, N., and Lühr, H.: The magnetosheath region adjacent to the dayside magnetopause: AMPTE/IRM observations, J. Geophys. Res., 99, 121-141, 1994.

Ruohoniemi, J. M. and Baker, K. B.: Large-scale imaging of highlatitude convection with Super Dual Auroral Radar Network HF radar observations, J. Geophys. Res., 103, 20 797-20 812, 1998.

Samson, J. C. and Rankin, R.: The coupling of solar wind energy to MHD cavity modes, waveguide modes, and field line resonances in the Earth's magnetosphere, in Solar Wind Sources of Magnetospheric Ultra-Low-Frequency Waves, Geophys. Monogr. Ser. 81, 1-11, AGU, Washington, D.C., 1994.

Sandholt, P. E., Farrugia, C. J., Burlaga, L. F., Holtet, J. A., Moen, J., Lybekk, B., Jacobsen, B., Opsvik, D., Egeland, A., and Lepping, R.: Cusp/cleft auroral activity in relation to solar wind dynamic pressure, interplanetary magnetic field $\mathrm{B}_{z}$ and By, J. Geophys. Res., 99, 17 323-17342, 1994.

Sibeck, D. G.: A model for the transient magnetospheric response to sudden solar wind dynamic pressure variations, J. Geophys. Res., 95, 3755-3771, 1990.

Slinker, S. P., Fedder, J. A., Hughes, W. J., and Lyon, J. G.: Response of the ionosphere to a density pulse in the solar wind: simulation of traveling convection vortices, Geophys. Res. Lett., $26,3549-3552,1999$.

Starkov, G. V.: Auroral heights in the polar cap, Geomagn. Aeron., Engl. Transl., 8, 28-32, 1968.

Vasyliunas, V. M.: Mathematical models of magnetospheric convection and its coupling to the ionosphere, in Particles and Fields in the Magnetosphere, edited by B. M. McCormac, 60-71, D. Reidel, Norwell, Mass., 1970.

Volkov, M. A. and Maltsev, Yu. P.: Flute instability of the inner plasma sheet boundary, Geomagn. Aeron., Engl. Transl., 26, 671-673, 1986.

Vorobyev, V. G.: Behavior of the dayside auroras after SC and SI, in Structure of magnetic-ionospheric disturbances, Leningrad, "Nauka", (in Russian) 126-132, 1977.

Zhou, X. and Tsurutani, B. T.: Rapid intensification and propagation of the dayside aurora: Large scale interplanetary pressure pulses (fast shocks), Geophys. Res. Lett., 26, 1097-1100, 1999. 